\title{
A PERCEPÇ̃̃O DOS JOVENS RESIDENTES EM ÁREAS DE SEGREGAÇÃO SOCIOESPACIAL SOBRE A POLÍCIA EM LONDRINA
}

\author{
Jesuel Sergio Lopes (Ciências Sociais - UEL) \\ Prof $^{a}$. Dione Lolis (orientadora)
}

\section{RESUMO}

Esta pesquisa busca conhecer a percepção dos jovens residentes em áreas de segregação socioespacial de Londrina sobre a polícia, em especifico sobre o projeto Unidade Paraná Seguro de Londrina, no Jardim União da Vitória. Analisa como se dá a relação entre os jovens e a polícia, em seu cotidiano, considerando as suas condições de vida, e as perspectivas de futuro, a partir de uma abordagem qualitativa, com observações de campo, entrevistas e de análise etnográfica, focada em figuras "comuns", ou seja, em jovens que não estão organizados em instituições políticas. Os sujeitos desta pesquisa são os jovens estudantes da Educação de Jovens e Adultos do ensino fundamental e médio, moradores no Jardim União da Vitória. Verifica que os jovens não reconhecem uma real eficiência na política de aproximação da polícia com a comunidade, como propõe o projeto UPS. Os jovens se preocupam com a violação da própria integridade física e as suas expectativas futuras não ultrapassam o campo de ampliação da repressão.

Palavras chave: juventude, segregação socioespacial, polícia.

\section{INTRODUÇÃO}

Esta pesquisa busca desenvolver uma análise sobre a percepção dos jovens pobres de áreas de segregação socioespacial em relação à Polícia Militar e interpretar a relação destes jovens com a polícia, assim como, discutir sobre a eficiência e a legitimidade do poder que ela exerce, tanto ideológico como quanto ao monopólio da força física. Concomitantemente, busca saber como esses jovens veem as ações policiais a as suas estratégias de aproximação com a comunidade, e contribuir para diminuir o déficit acadêmico sobre esse tema de tamanha importância para as ciências sociais.

Para atingir tais objetivos, optamos por uma abordagem de cunho qualitativo, por meio de uma pesquisa de campo, através de entrevistas semiestruturadas, tendo como referência Maria Isaura Queiroz (1991, p. 87), que nos elucida sobre quais as melhores formas de fazer uma entrevista e de transcrevê-la. Ela analisa que no momento que o pesquisador transcreve, ele revive toda cena e, a cada vez que (re)escuta a gravação, tem a possibilidade de explorá-las mais a fundo. Com essa preocupação, realizamos entrevistas com jovens estudantes da Educação de Jovens e Adultos (EJA), do Colégio Estadual Prof. ${ }^{\text {a }}$ Rina Maria de Jesus Francovig, do Ensino Médio e Fundamental II, no período noturno do último ano, residentes no Jardim União da Vitória, em Londrina-PR, com idades entre 15 e 29 anos; sendo 3 (três) jovens do sexo feminino (16, 23 e 28 anos) e 2 (dois) do sexo masculino (17 e 23 anos). Estas entrevistas subsidiaram a materialização da percepção que os jovens de uma comunidade segregada têm sobre a polícia local. 


\section{SEMINÁRIO DE PESQUISA EM CIÊNCIAS HUMANAS - SEPECH \\ Humanidades, Estado e desafios didático-científicos \\ Londrina, 27 a 29 de julho de 2016}

\section{SEGURANÇA PÚBLICA E POLÍCIA}

Antes mesmo de discutir sobre a percepção dos jovens em relação à polícia, buscamos primeiro apresentar o conceito de segurança pública, recorrendo a José Damião Trindade (2002), e à sua análise sobre os direitos humanos na perspectiva de Marx e Engels. Em sua concepção, a segurança pública burguesa é um meio, entre outros aspectos, que impossibilita a emancipação plena do ser social, pois ela leva o indivíduo a reconhecer no outro um obstáculo para exercer a sua liberdade e não uma necessidade objetiva de realizá-la, como defende a teoria marxista. Para Karl Marx (apud TRINDADE, 2002, p.45), a segurança é:

[...] "o conceito social supremo da sociedade burguesa, conceito de polícia, segundo o qual toda a sociedade somente existe para garantir a cada um de seus membros a conservação de sua pessoa, de seus direitos e de sua propriedade", o que impede a superação do egoísmo. "A segurança, pelo contrário, é a preservação deste".

Fez-se necessário entender ainda como está estruturada a Polícia Militar no Brasil e, assim, recorrer aos estudos que mostram essa configuração.

A polícia brasileira, na análise de Fernanda Kilduff (2013), apresenta um sistema análogo ao modelo estadunidense, tendo em vista o modelo teórico desenvolvido por Loïc Wacquant $(2005,2007)$, em sua teoria da gestão da miséria por parte do Estado capitalista, que implica em maior controle da população pobre por meio de uma legislação punitiva. Esse controle fica evidente na forma como a polícia brasileira vem se militarizando cada vez mais, desde a ditadura militar de 1964, apoiando-se numa guerra ao tráfico de drogas, como uma justificativa para aumentar a violência contra os pobres, principalmente os jovens. A intervenção policial serve, ao mesmo tempo, como forma de especular o mercado da violência, que ganha destaque no sistema econômico não oficial.

Vera Batista (apud KILDUFF, 2013) fala da criação de um novo inimigo interno. Ela afirma que o controle repressivo convergiu então para a confecção do novo estereótipo de criminoso, que foi de trabalhadores e intelectuais, geralmente sindicalizados e/ou membros de partidos políticos, para os jovens pobres. Diz ainda que "[...] O inimigo, antes circunscrito a um pequeno grupo, se multiplicou nos bairros pobres, na figura do jovem traficante" (p.6).

Percebe-se que se criam estereótipos como forma de desumanizar os pobres que os colocam como um "mal" a ser combatido. Eugenio Zaffaroni (apud KILDUFF, 2013, p. 4), cita que "a essência do tratamento diferenciado que se atribui ao inimigo consiste em que o direito lhe nega sua condição de pessoa. Ele é considerado sob o aspecto de ente daninho ou perigoso [...]"

É notável como esse processo afeta violentamente os jovens. Os dados estatísticos de 2012, analisados por Júlio Waiselfsz (2014), revelam uma taxa de homicídios de 57,6 jovens para 100 mil habitantes, enquanto a taxa geral de homicídios no Brasil é de 29,0 por cem mil; número que mostra o quanto a violência atinge de forma brutal a juventude. Em Londrina, como fica evidente na pesquisa realizada por Dione Lolis (2010, p. 223) sobre as mortes de jovens de 15-24 anos, no período de 2000-2003, do total de mortes em homicídios, 93\% tiveram como meio a arma de fogo 


\section{SEMINÁRIO DE PESQUISA EM CIÊNCIAS HUMANAS - SEPECH \\ Humanidades, Estado e desafios didático-científicos \\ Londrina, 27 a 29 de julho de 2016}

e, em sua maioria, residentes em bairros com alto índice de vulnerabilidade social, como o Jardim União da Vitória.

\section{CONCEITUANDO JUVENTUDE(S)}

É importante também conceituarmos juventude, ou melhor, juventude(s). Tendo em vista a abordagem realizada antes, pontuaremos juventude a partir da concepção desenvolvida por Marialice Foracchi, apresentada por Maria Helena Augusto (2005). Para Foracchi, juventude se define por três características: por ser uma fase da vida, pela demonstração de força renovadora e sua percepção (num âmbito geral da realidade, para além do espaço cronológico) para a construção de um estilo próprio de existência e de sua realização de seus propósitos pessoais (apud AUGUSTO, 2005, p. 20).

Desta forma, na concepção de Foracchi, enquanto uma fase da vida que antecede a maturidade, como período da construção do eu, indispensável para a formação do indivíduo social, juventude remete-se à uma etapa decisiva de revelação da vida e da história. Todavia, ela dependente diretamente das possibilidades de inserção social postas, para a realização de suas potencialidades e de recursos a ser mobilizados para tal. Com isso, as juventudes se fazem mediante o espaço que ocupam e pelas trajetórias que lhes são colocadas, o que leva a entender que não há uma juventude una, mas uma diversidade influenciada pelas diferenças sociais e econômicas, que estão inseridas de modo a privilegiar uma, em detrimento de outra.

Assim, o que se pode afirmar é que as juventudes são uma construção social e, por isso, estão sujeitas às determinações sociais, ou seja, que a sociedade possibilita a existência de diversas juventudes, dependendo dos extratos sociais que ocupam, impondo ou possibilitando a construção pelos jovens dos seus modos de ser.

Por outra via, para Foracchi, juventudes são entendidas também como uma força dinamizadora e sujeitos de transformações sociais. Desta maneira, está presente na juventude a procura por uma sociedade mais justa, a denúncia das desigualdades sociais e a revelação dos modelos de opressão existentes, como também, lhe é própria a flexibilidade diante de novas alternativas, da maior facilidade em adaptarem-se às suas novas realidades e construir novos modos de existência antes desconhecidos.

Com isso, Foracchi nos possibilita contextualizar essas características em uma realidade atual, que, por um lado, existe uma valorização da juventude como uma forma de incorporar as tendências de constantes inovações próprias da sociedade contemporânea (no sentido do desenvolvimento tecnológico e da flexibilização do trabalho e das relações sociais) e também pela juvenilização da sociedade por meio do consumo. Por outro, a falta de possibilidades para que os jovens construam sua história, seu estilo próprio de existência, uma sociedade que, ao invés de absorver as demandas colocadas pela e/ou para as juventudes, opta-se por exercer um controle exacerbado (criminalizando-os), principalmente sobre a juventude pobre e negra, numa defesa contraditória do status quo. Para Helena Abramo (1997), ao falar dos programas desenvolvidos para atender os jovens do Brasil:

[...] parece estar presente na maior parte das abordagens relativas aos jovens, tanto no plano da sua tematização com das ações a eles dirigidas, uma grande dificuldade de considerar efetivamente os jovens 


\section{SEMINÁRIO DE PESQUISA EM CIÊNCIAS HUMANAS - SEPECH \\ Humanidades, Estado e desafios didático-científicos \\ Londrina, 27 a 29 de julho de 2016}

como sujeitos, mesmo quando é essa a intenção, salvo raras exceções; uma dificuldade de ir além da sua consideração como "problemas social" e de incorporá-los capazes de formular questões, significativas, de propor ações relevantes dialógica com outros autores, de contribuir para a solução dos problemas sociais, além de simplesmente sofrê-los ou ignora-los.

Desse modo, diante das dificuldades encaradas pela juventude de se fazer no mundo um modo de ser, um estilo próprio de existência, o qual está na dependência de alternativas de inserção social a ela disponível, além de recursos a serem mobilizados, o que parece é que a juventude se encontra em um mundo onde não lhe é reservado qualquer espaço. Em nossa análise, que apresentaremos a seguir, com base nos resultados desta pesquisa, a juventude, principalmente a pobre e a negra, no que se refere à segurança pública, devido à lógica do capitalismo e às prioridades distintas, sofre uma constante criminalização (vista como inimigo a ser combatido) em benefício de uma ordem cada vez mais insustentável.

\section{SENTIMENTO DE INSEGURANÇA E TOLERÂNCIA À REPRESSÃo POLICIAL}

Um dos elementos que merece um olhar atento nesta pesquisa é o sentimento de medo e insegurança que, em várias ocasiões, leva os jovens a encontrarem soluções imediatas, como verificamos transversalmente na maioria das opiniões dos jovens, contribuindo para o seu isolamento dentro de casa ou para a busca da segurança pelas próprias mãos, ou seja, de soluções individuais/particulares para um problema coletivo/público. Norbert Elias (apud MORAIS, 2006, p. 169) nos dá uma boa interpretação do significado do medo relatado pelos jovens.

"O alto nível de exposição aos perigos tende a aumentar a emotividade das respostas humanas. Essa alta emotividade da resposta diminui a possibilidade de avaliação realista em relação a ele; sob pressão de fortes emoções, um comportamento relativamente não realista diminui a possibilidade de colocar o processo sob controle [...]".

Pode-se dizer, porém, que o grau de violência existente em uma comunidade pode ser diferente de outra e, desta forma, causar maior ou menor comoção de uns grupos em relação a outros, como nos chama a atenção Paul Cheigny (apud MACHADO; NORONHA, 2002, p. 188).

A violência policial contra indivíduos e grupos, também chamada de violência oficial, é uma constante nas sociedades modernas e contemporâneas. Contudo, a sua forma varia conforme o grau de tolerância, governamental ou popular, levando a que, em certos lugares, haja mais vigilância sobre a ação policial do que em outros. Assim, se em certas cidades o seviciamento de um indivíduo pertencente a um grupo étnico ou social discriminado, é suficiente para provocar um debate público acalorado, em outras, fatos dessa ordem ou mais graves não despertam igual interesse na mídia ou na população como um todo. 


\title{
XI SEMINÁRIO DE PESQUISA EM CIÊNCIAS HUMANAS - SEPECH \\ Humanidades, Estado e desafios didático-científicos \\ Londrina, 27 a 29 de julho de 2016
}

Com isso, nota-se que a realidade social influencia os meios desenvolvidos para promover a segurança pública. E esta pesquisa buscou analisar a opinião que os jovens de áreas segregadas de Londrina têm sobre a atuação da Polícia Militar, levando em consideração que está em funcionamento desde dezembro de 2012 uma Unidade Paraná Seguro (UPS), localizada no Jardim União da Vitória, na região sul da cidade.

A UPS é uma polícia inspirada na Unidade Polícia Pacificadora (UPP), implantada no Rio de Janeiro, e, de acordo com a Secretaria de Segurança, da Justiça, Cidadania e Direitos Humanos do estado do Paraná (PARANÁ, 2015a), surge com o seguinte objetivo:

\begin{abstract}
Desenvolver ações integradas de mobilização social nas comunidades onde estão localizadas as Unidades Paraná Seguro (UPS), visando a sustentabilidade e efetividade do Programa Paraná Seguro por meio da sensibilização e envolvimento das comunidades em ações que contribuam para melhorar a segurança pública e o desenvolvimento socioeconômico local.
\end{abstract}

Ela surge, portanto, com o objetivo de aproximação com a comunidade, o que coloca novos pontos de vista sobre a instituição e sua relação com esses jovens, moradores do bairro.

No desenvolvimento das relações sociais capitalistas, surge a necessidade de formas de controle social que se materializam em determinadas políticas de Estado, como a segurança pública, e em instituições estatais, como a polícia. Esses meios de controle social se distribuem de forma desigual na sociedade e percebemos como os jovens são muito mais atingidos pela repressão policial, por meio de uma política de guerra aos pobres. Desta forma, passamos ao nosso foco principal que é conhecer a percepção dos jovens sobre a polícia e também suas perspectivas futuras, além de testar a hipótese de melhorias advindas da UPS.

\section{A POLÍCIA NA CONCEPÇÃO DOS JOVENS}

De início, percebe-se uma noção de segurança pública que mostra uma enorme preocupação dos jovens com a segurança física e de seus bens. Como revelam os jovens quando definem segurança pública: "como poder andar nas ruas sem ter medo de bandido" (J.3, fem. 28 anos) ou "não ter medo de confusões" (J.4, fem. 16 anos). Ou seja, essa percepção inicial da segurança pública dificulta pensá-la como um todo, ou do grupo a qual pertencem, mas resguardar-se do todo como se não fizessem parte do mesmo, denotando uma percepção individualista de segurança pública.

Ainda, apresenta-se fortemente entre os jovens um sentimento geral de insegurança. Quando questionados sobre o lugar onde se sentem mais seguros, majoritariamente afirmam que é dentro de casa: "Dentro da minha casa, trancada com o cadeado lá fora" (J.3, fem. 28 anos); "Só em casa" (J.5, fem. 22 anos). Ao indagarmos o porquê, citam: "Ah, saio às vezes [na rua] e dá um confronto, alguma coisa, aí não tem como, ninguém por perto, não tem como se defender" (J.5, fem. 22 anos) "É tipo assim, você sai na rua, começa o tiroteio, para onde você corre? Não tem lugar!" (J.4, fem. 16 anos). O contrário é válido sobre o lugar onde eles sentem-se menos seguros: "na rua, 


\section{SEMINÁRIO DE PESQUISA EM CIÊNCIAS HUMANAS - SEPECH \\ Humanidades, Estado e desafios didático-científicos \\ Londrina, 27 a 29 de julho de 2016}

(J.3, fem. 26 anos). Sobre o porquê, a mesma entrevistada responde: "saiu para fora da casa já vem uns outros e, às vezes, uns abusam também; aí a gente fica com medo".

Aqui se revela a esfera mais cruel gerada por uma segurança pública, ou insegurança pública, que não tem como objetivo a proteção integral dos jovens, mas que, ao contrário, os colocam num palco de guerra onde não se tem garantia de sua integridade física; o mínimo que os jovens reivindicam como segurança pública. Vemos ainda que nesse momento o medo da perda de bens (roubos, furtos) não aparece, o que demonstra ser secundário; talvez falso ou ideológico.

Segundo Barry Glassner (apud MORAIS, 2006), entende-se o medo (como nos trechos das entrevistas citados acima) no sentido de contínua insegurança. Assim, criase uma cultura do medo, que é incorporada pelos atores e grupos sociais e esses os colocam em prática, num generalizado sentimento de insegurança. Glassner afirma que esse generalizado sentimento de insegurança (alta exposição aos perigos) pode levar esses jovens à perda do controle real da situação, e do entendimento da segurança pública no sentido de proteção de si e do todo, e, mais à frente, apresentarão como solução a necessidade de uma iniciativa externa, sem entender que, em grande medida esse resultado é expressão da realização dessa segurança pública externa que veem como possibilidade de solução.

Outra jovem se diferencia um pouco no seu discurso em relação aos motivos, "Pela falta de policiamento, pela falta de estrutura, tipo luz, essas coisas, e muita bandidagem também" (J.3, fem. 28 anos). Esta opinião, por um lado, aproxima-se mais dos elementos que promovem segurança pública, por outro, revela o estigma que justifica a insegurança, ou seja, a ideia acrítica de bandido que frequentemente é usada para aumentar a repressão aos pobres. Apenas um jovem defende que o motivo é o desconhecimento da vizinhança: "Em um lugar estranho que eu nunca fui, não conheço nada" (J.2, masc. 17 anos). O que não significa ser fruto de uma fraca sociabilidade, mas indica que esse jovem, por não confiar na polícia, se junta a outros jovens para se auto organizarem e, desta forma, em uma comunidade "estranha", não tendo seus pares como referência, se sente menos seguro; destarte, não diferencia em quase nada da percepção individualista de segurança pública.

O que há em comum nas opiniões dos jovens é o sentimento de insegurança e medo, ou seja, revela que o medo está presente tanto no perigo de ser assaltado, quanto de sofrer violência por "bandido" ou pela polícia: falta de polícia e/ou confiança na polícia.

Quanto à responsabilidade por garantir a segurança pública, as opiniões são variadas: "a polícia e os próprios moradores" (J.1, masc. 15 anos). Um jovem opina que "cada um tem que garantir sua própria segurança, já que a polícia não o faz" (J.2 masc. 17 anos). Para outros, cabe ao Estado. Apenas uma jovem cita a educação e outros serviços públicos, como a iluminação de ruas e escolas, enquanto medidas importantes e função específica do Estado.

Nessa questão, as variadas opiniões expressas, desde um jovem defender uma relação harmônica entre polícia e moradores, sustentando esse argumento em toda entrevista, outro aponta uma incompatibilidade total entre a polícia e os indivíduos da comunidade, e o restante dos jovens indicam as medidas a serem implementadas pelo Estado, como responsável. O entendimento majoritário é de que a responsabilidade pela segurança é do Estado, o que traz duas consequências negativas: por um lado legitima a atuação dos governos, mesmo que estes não estejam correspondendo às necessidades 


\section{SEMINÁRIO DE PESQUISA EM CIÊNCIAS HUMANAS - SEPECH \\ Humanidades, Estado e desafios didático-científicos \\ Londrina, 27 a 29 de julho de 2016}

dos jovens, por outro lado, dificulta a participação cidadã, pois a grande maioria não reconhece como necessária a sua participação no processo de definição do modelo de segurança pública que melhor os atendam.

Sobre o que eles pensam da atuação da Polícia Militar, inicialmente eles dividem opiniões, uns defendendo-a como positiva, por garantir a ordem e, outros, como negativa, por ser violenta e/ou por não atender, quando procurada, como argumenta o seguinte jovem:

\footnotetext{
É, eu vejo por um lado muito competente os serviços deles [da polícia], embora muitas pessoas falem mal, muitas pessoas falem que são incompetentes, que é isso, que é aquilo, mas eu vejo um lado muito bom nisso porque, sem isso, já ia se tornar um caos total. Assim, com essa segurança, já é esse tumulto, sem isso então seria pior (J.1, masc.15 anos)
}

Outros jovens citam: "Eles agem errado, tipo, bate para depois perguntar; é isso, e sem ter suspeita começam a bater" (J.4, fem. 16 anos). Uma jovem defende também que: "[agem] mal. Eles, às vezes, passam por cima e não veem o que está acontecendo; eles fingem que não" [veem e não atendem as pessoas?]. "Isso!" (J.5, masc. 22 anos). Nesse sentido, a maioria expõe sua opinião colocando em xeque a polícia, exceto um jovem, que entende que se não houvesse a polícia o caos seria pior. O que existe de comum em todas as opiniões é a perspectiva caótica de segurança pública, que incomoda os jovens, de forma desigual.

Desta forma, quando questionados se eles conheciam a UPS, todos revelam que sim, pelo menos de vista. Sobre a visão quanto a atuação dessa polícia, alguns citam: "Está boa, mudou bastante [...] mudou, ali, que antes era muito movimento" [Tinha mais alguma coisa que incomodava e a polícia veio e mudou? ]. "Assim, o tráfico. É, o tráfico, tirou daí, pois, no começo, deu muito trabalho, depois acostumou" [No começo, aumentou a violência?]. "É, aumentou. [A violência por parte de quem?]. Dos traficantes. [E a polícia, também foi violenta ou não?]. "Assim, eles atacavam [os traficantes] e os policiais revidavam, depois eles se acostumaram e aí ficou normal" (J.2, masc. 17 anos).

Ou seja, na opinião desses jovens, quando a UPS chegou ao bairro o local era "muito movimentado" e ela agiu de forma a amenizar os conflitos. Argumentam que no início houve grande tensão entre polícia e os traficantes da região e que a violência aumentou; os traficantes atacavam de um lado, e a polícia revidava do outro. Nesse sentido o que alguns dos jovens expressam o que se observa ser uma prática comum na entrada da UPS nos bairros onde foi instalada no Paraná, ou seja, na sua entrada nos bairros, busca fazer uma varredura em busca de drogas, de presos foragidos e, principalmente, de armas de fogo, para depois implementarem a proposta de aproximação que defende.

Contrariamente, outros jovens ressaltam que os policiais da UPS são sossegados/ tranquilos, como nestes depoimentos: “É, eles são mais sossegados, eles são mais tranquilos" (J.4, fem. 16 anos); “Ah, eles são mais tranquilos [...]. É melhor, dá para ver ao passar ali, tem um que está sentadão e tem uns que estão conversando" (J.5, fem. 22 anos). Estes jovens argumentam que os policiais ficam o dia todo na UPS e que 


\section{SEMINÁRIO DE PESQUISA EM CIÊNCIAS HUMANAS - SEPECH \\ Humanidades, Estado e desafios didático-científicos \\ Londrina, 27 a 29 de julho de 2016}

não interveem muito na comunidade, e, por sua vez, que essa polícia não atende os chamados, ou seja, não fazem a menor diferença.

Desse modo, entende-se que a polícia "toma"/entra no bairro e domina os conflitos mais explícitos. Posteriormente, na percepção dos jovens, a política de aproximação é a não atuação, ou a não interferência dentro da comunidade, ou seja, não tem muita relevância sua presença no bairro, por isso, é menos violenta.

Quanto à prestação de outros serviços não repressivos pela UPS, as respostas foram quase unânimes: desconhecem, exceto um jovem que afirma que eles "dão informações" (J.1, masc. 15 anos), por vez, um serviço, diremos, pouco relevante, pois, não a diferencia de outra polícia. Surge desta forma, um fator extremamente relevante para entender a política de aproximação da UPS, ou seja, que apesar de os relatórios da polícia (PARANÁ, 2015b) apresentarem que nesses dois anos de atuação mais de 5.500 serviços sociais não referentes à repressão foram prestados, como, cadastramento em projetos sociais para pessoas de baixa renda, fazer documento de CPF e RG, auxiliar na busca por empregos, entre outros, os jovens revelaram não conhecer qualquer serviço da polícia UPS que não fossem a repressão.

Tais opiniões podem indicar um fracasso no projeto de polícia cidadã, desenvolvido pela UPS. Podemos notar, no máximo, uma relação de indiferença, sendo que essa polícia precisa mostrar, no mínimo, que está na comunidade para prestar o real serviço de segurança pública - do ponto de vista da segurança pública do Estado moderno, segundo a concepção weberiana -, que, além do controle pela força, é principalmente a prestação de serviços de prevenção. Deste ponto de vista, de garantir os direitos sociais (em geral, direcionados ao indivíduo), prezando pela garantia de um ambiente seguro, harmônico e de paz.

Quanto à abordagem policial, uma jovem opina que a abordagem da Ronda Ostensiva Tática Móvel (ROTAN) é mais violenta que a da UPS, e os demais argumentam que quase não veem a polícia no bairro. Ou seja, isso reforça a ideia de política da indiferença.

Sobre a questão se houve melhora da segurança com a vinda da UPS para o bairro, alguns acham que apesar de não enxergarem muito o serviço deles, só a presença inibe as ações dos bandidos, citando como exemplo: "[...] só por estar ali, os bandidos meio que se escondem um pouco" (J.3, fem. 28 anos). Outros, que não, pois, a polícia não representa segurança para os jovens: “[...] os jovens não se sentem mais seguros por causa de drogas, esse tipo de coisa aí; não tem como escapar delas" (J.4, fem. 16 anos). O que essa jovem revela é que a UPS, mesmo tendo resultado positivo referente aos crimes mais explícitos, não traz mais segurança para os jovens, pois os mesmos continuam sendo reféns da guerra às drogas, ou, melhor dizendo, da guerra aos pobres, como argumenta Wacquant (2007), ainda que a violência seja algo inevitável, o que dificulta pensar em uma saída.

Por fim, quando questionados sobre qual seria a melhor forma de polícia, surge um consenso nas respostas. Até mesmo os que disseram não acreditarem na polícia defendem mais abordagens, policiamento ostensivo e rapidez no atendimento dos chamados, citando como exemplos: "Sabe, fiscalizando bastante, andando bastante, abordando; eu não sou contra abordagem" (J.3, fem., 28 anos). "É, fazendo [mais ronda] todo o dia, no mesmo horário, à noite. Também, coisa que eu nunca vi eles fazendo é a ronda nas escolas" (J.4, fem. 16 anos). Ou seja, no quesito mais importante, os jovens, apesar de alguns discordarem radicalmente em determinados aspecto da segurança 


\section{SEMINÁRIO DE PESQUISA EM CIÊNCIAS HUMANAS - SEPECH \\ Humanidades, Estado e desafios didático-científicos \\ Londrina, 27 a 29 de julho de 2016}

pública e das polícias (PM, UPS), não conseguem vislumbrar caminhos diferentes da concepção individualista e burguesa de segurança pública. O que esses dados parecem apontar é que essa concepção de segurança pública, nesse momento, supera a realidade concreta dos jovens, impedindo-os de, ao menos, pensarem em novas formas de segurança pública.

\section{CONCLUSÃO}

A bibliografia e os relatos dos jovens entrevistados nos faz concluir que a juventude, particularmente a pobre e a negra, continua sendo maioria entre as vítimas desse modelo de segurança pública repressivo. Seja como refém do medo e da insegurança real ou ficcional e da violência de fato, como expressam os dados estatísticos, seja como refém da exploração, alienação e exclusão social e tantas outras violências.

Um fator relevante desta pesquisa se refere ao método aplicado, que em busca de colher opiniões dos jovens sobre a polícia, no qual foram utilizadas observações e entrevistas individuais, gravadas, com perguntas semiestruturadas, possibilitou indagar de diversas formas uma mesma questão, e assim extrair uma concepção mais profunda do indivíduo e relatos que talvez não fossem possíveis em entrevista coletiva ou questionário fechado. Buscou-se dar voz aos jovens e ser o mais fiel possível em retratar e analisar suas opiniões, sempre procurando fazer uma relação com o macro, pois entendemos que as opiniões dos mesmos exprimem uma totalidade da qual são membros atuantes.

Ainda, sem receio de dar um tratamento sociológico às opiniões, ou seja, de posicionarem suas defesas referentes à polícia, tendo em vista que nem sempre estão em condições de expressarem de forma clara suas ideias, revelam as contradições e coerências em seus discursos. Esta pesquisa não tinha qualquer interesse em fazer juízo de valor dos relatos dos jovens, por outro lado, tendo claro o posicionamento não neutro dos pressupostos que permearam o seu percurso metodológico.

Com isso, note-se que esses jovens em especifico compartilham ideias sobre segurança pública e polícia, medo/insegurança e suas reivindicações, mas a maioria delas não ultrapassa a exigência de garantia de integridade física e, como solução imediata que encontram, buscam o isolamento dentro de casa, como único ambiente seguro, ou a segurança pelas próprias mãos. Isso individualiza sua segurança e a maioria ainda vê o Estado como responsável por garantir a segurança pública, o que os deixa na dependência de uma política que não deixa emergir soluções concretas.

No que se refere ao projeto de polícia cidadã UPS e à hipótese apresentada, podemos extrair desta pesquisa, que ela não é de uma polícia cidadã, mas ao contrário, uma polícia indiferente. Essa polícia é indiferente na perspectiva de alguns jovens e, de início, combateu os crimes mais explícitos ou supostos atos de "desordem" que eles consideram como um ambiente "muito movimentado", e, em geral, defendem que no decorrer de sua gestão não interferem de forma relevante na comunidade, ou seja, o que torna essa polícia menos violenta não é a forma diferente de atuação, mas, a não atuação.

Por outra via, os serviços apresentados pela polícia como forma de aproximação e de não repressão, não são compartilhados pelos jovens, o que indica também uma 


\section{SEMINÁRIO DE PESQUISA EM CIÊNCIAS HUMANAS - SEPECH \\ Humanidades, Estado e desafios didático-científicos \\ Londrina, 27 a 29 de julho de 2016}

incompatibilidade com os serviços apresentados e a demanda real de segurança pública dos jovens. No que se refere à violência policial, ela aqui aparece suavizada, pois a maioria desses jovens estudantes não chegou a ser abordada pela UPS ou relatou alguma ação concreta de repressão dessa polícia, o que impossibilita confirmar se realmente ela é menos violenta.

Enfim, mesmo que os jovens tenham um assustador sentimento de medo - da violação da própria integridade física -, as suas expectativas futuras não saem do campo de ampliação da repressão, ou seja, do policiamento mais ostensivo.

\section{REFERÊNCIAS}

ABRAMO, H. W. Considerações sobre a tematização social da juventude no Brasil. In: Revista Brasileira de Educação, USP, mai/jul/ago 1997 n ${ }^{\circ}$; set/out/nov/dez 1997 nº6, p. $25-36$

AUGUSTO, M. H. O. Retomada de um legado intelectual: Marialice Foracchi e a sociologia da juventude. In: Tempo Social; revista de sociologia da USP, v. 17, n. 2, nov. 2005, p. 11-33.

KILDUFF, F. Segurança Pública no Brasil: estratégia militarizada da gestão da pobreza. XIX Congresso Latino-americano de Sociologia. ALAS. Chile, 2013. Disponível em <http://actacientifica.servicioit.cl/biblioteca/gt/GT4/GT4_KilduffF.pdf $>$. Acesso em 12 jun. 2014.

LOLIS, D. Homicídios de jovens e segregação sócio espacial em Londrina. In: Semina: Ciências Sociais e Humanas. Londrina: UEL, v,31, n,2, p, 221-240, jul/dez 2011. Disponível em <http://www.uel.br/revistas/uel/index.php/seminasoc/article/view/5082>. Acesso em 12 jun. 2014.

MACHADO, E.P.; NORONHA, C.V. A polícia dos pobres: violência policial em classes populares urbanas em classes populares urbanas. In: Sociologias. Porto Alegre: UFRGS, 2002, p. 188-221. Disponível em $<$ http://www.scielo.br/pdf/soc/n7/a09n7.pdf >. Acesso em 12 jun. 2014.

MORAIS, P.R.B. Juventude, medo e violência. In: Centro de Estudos em segurança pública e Direitos Humanos. Curitiba: UFPR, 2006. Disponível em $<$ http://www.ipardes.gov.br/pdf/cursos_eventos/governanca_2006/gover_2006_01_juve ntude_medo_pedro_bode.pdf $>$. Acesso em 26 jun. 2014.

PARANÁ. Programa de Ações Integradas de desenvolvimento de cidadania: sociedade em movimento para a cultura da paz. Governo do Paraná. Curitiba, 2015a. Disponível em $<$ http://www.ups.pr.gov.br/modules/conteudo/conteudo.php? Conteúdo $=2>$ Acesso em 23 ago. 2015.

. UPS. Cidadania sociedade em movimento para a cultura da paz relatório de ações. Governo do Paraná. Curitiba, 2015b. Disponível em: 
$<$ http://www.ups.pr.gov.br/arquivos/File/RelatorioFeiraUPS_UniaoVitoria_Londrina.pd f $>$ acesso em 16 set. 2015 .

QUEIROZ, M.I.P. Variações sobre a técnica de gravador no registro da informação viva, São Paulo: Ed. T.A Queiroz, 1991. In: SIMSOM, O. Experimentos com Histórias de Vida (Itália-Brasil). São Paulo: Vértice, 1988, p. 14-43.

WACQUANT, L. Os condenados da cidade: estudos sobre a marginalidade avançada. 2. ed. Rio de Janeiro: Revan, 2005.

Punir os Pobres: a onda punitiva. 3. Ed. Rio de Janeiro: Revan, 2007 (Coleção Pensamento Criminológico n. 6).

WAISELFISZ. J.J. Mapa da Violência 2014. Os Jovens do Brasil. Brasília, DF: Cebela; Flacso, 2014. Disponível em <wwwjuventude.gov/juventudeviva $>$. Acesso em 12 jun. 2014. 